\title{
Sublimation for Enrichment and Identification of Marker Compounds in Fruits
}

\author{
Manuel Gronbach $^{1} \cdot$ Laura Kraußer $^{1} \cdot$ Timo Broese $^{1} \cdot$ Christina Oppermann $^{1} \cdot$ Udo Kragl $^{1,2}$ (D)
}

Received: 12 August 2020 / Accepted: 27 December 2020 / Published online: 14 January 2021

(C) The Author(s) 2021

\begin{abstract}
In this article, we describe the benefits of sublimation for natural product and food chemistry. The direct sublimation of substances from dried plant powders has not received much attention in research in the past, just like the sublimation of substances from dried plant extracts. We used sublimation to study dried sea buckthorn berry powders and dried sea buckthorn berry extracts. The results of the powder sublimations were compared to that of dried chokeberry, wolfberry, and European cornel powder. 52 marker substances of which 27 are specific for sea buckthorn were found in the sea buckthorn powder sublimates using LC/MS. The majority of them are not described in the literature and were obtained by direct sublimation. Accordingly, sublimation can help to identify new plant constituents. Our identification method was validated by the analysis of four commercially available fruit powders. The sea buckthorn powder showed an almost $80 \%$ correlation with the determined marker substances, whereas the other fruit powders did not achieve more than $38 \%$ correlation. The sublimates of sea buckthorn extracts show additional marker substances compared to the fruit powder sublimate, and we think that both techniques can be used to fight food fraud.
\end{abstract}

Keywords Sublimation $\cdot$ Sea buckthorn $\cdot$ Natural product $\cdot$ Identification $\cdot$ Food fraud $\cdot$ Enrichment

\section{Introduction}

Plant-based products and isolated natural substances play a significant role in many areas of our life. Some of them are consumed directly in the form of food, including food additives and supplements that contribute to a healthy lifestyle. Other products such as plant extracts are employed in the production of ointments, creams, and other cosmetic products (Frede 2006). Because of their promising health properties, they are also extensively studied and their active ingredients are isolated (Gurib-Fakim 2006). Between 1981 and 2014, for example, natural products and their derivatives accounted for approximately $26 \%$ of newly approved pharmaceuticals (Newman and Cragg 2016). To obtain these substances first,

Udo Kragl

udo.kragl@uni-rostock.de

1 Industrial and Analytical Chemistry, Department of Chemistry, University of Rostock, Albert-Einstein-Straße 3a, 18059 Rostock, Germany

2 Department Life, Light \& Matter, Faculty for Interdisciplinary Research, University of Rostock, Albert-Einstein-Straße 25, 18059 Rostock, Germany the plant material has to be extracted which is a key step in drug discovery.

Classical extraction methods which use organic solvents of different polarities, water, and their mixtures are still the most commonly used methods today. In addition to the well-known techniques such as maceration, percolation, and Soxhlet extraction, more modern methods such as ultrasound and microwave extraction are also employed. The use of ionic liquids as extraction medium is quite specific, whereas supercritical fluids are widely applied nowadays (Kassing et al. 2010). Volatile substances such as essential oils are still derived mainly by distillation techniques. Normally, extracts are complex mixtures of substances. Therefore, it is necessary to separate them to obtain certain classes of substances or pure compounds. To achieve higher purity products, there are multiple approaches which range from preparative planar chromatography to column chromatographic methods such as flash chromatography, highperformance liquid chromatography, or simulated moving bed chromatography to liquid-liquid isolation techniques such as counter-current chromatography (Sticher 2008; Bucar et al. 2013; Lin et al. 2015). These purification steps are cost intensive and time consuming, so methods that deliver a higher purity product are of great interest. 
Sublimation offers the possibility to obtain substances or mixtures of substances in higher purity. This is due to the fact that only few compounds tend to sublimate. However, by using low pressures in combination with elevated temperatures, more substances can be sublimated. Similar to distillation, the purity of the final product can be influenced by varying the sublimation parameters (Matz 1966). The application of sublimation as a method to obtain natural products out of plant material has gained only a small amount of attraction over the last decades. The majority of publications show sublimation as a final clean-up step to isolate pure natural compounds out of plant extracts (Kosuge and Kamiya 1962; Hargreaves et al. 1968; Burnett and Thomson 1967; Aoyagi et al. 1974; Kuzma et al. 2001; Guidoin et al. 2003). The direct sublimation of substances out of natural sources is mentioned significantly less in the literature (Glavin et al. 2006; Arvindekar et al. 2015). Since the accumulation of substances in the sublimate is an exclusive event, the process of sublimation is very interesting for the study of natural materials. It is also a solvent-free method, which requires only a little time and effort.

Regardless of whether the plant is used directly or in processed form, the quality of the product must be checked. In addition to protection against financial consequences of fraud, the health of the consumer is of course the priority, as the addition, absence, or exchange of ingredients can have fatal consequences (Spink and Moyer 2011). Both target and non-target analyses are performed to control raw materials and production goods. The former require one or better several known substances in the sample material and thus can be quantitative. Non-target analyses are qualitative and refer to unspecific signals, so that the data is seen as a fingerprint of the sample. Depending on the different raw materials and products, a variety of analytical equipment is required to enable data acquisition. Mass spectrometry (MS), polymerase chain reaction (PCR), and liquid chromatography (LC) are the most commonly used detection methods (Hong et al. 2017). Since people who commit fraud adapt to existing methods, a broad arsenal of techniques is desirable.

This study aims to demonstrate the benefits of utilizing sublimation as an additional method to obtain natural products from plant material. Additionally, it shows the possible application in quality control for raw materials and plant-based products in combination with $\mathrm{LC} / \mathrm{MS}$.

\section{Material and Methods}

\section{Chemicals}

All solvents used were of LC/MS or HPLC grade (CHROMASOLV ${ }^{\mathrm{TM}}$ ) and were purchased from Fisher
Chemical (Thermo Fisher Scientific, Schwerte, Germany). Cis-7-hexadecenoic acid ( $\geq 98 \%)$ and palmitoleic acid ethyl ester $(\geq 95 \%)$ were purchased from VWR (VWR International, Vienna, Austria). Analytical standards of (+)catechin, trans-p-coumaric acid, (-)-epicatechin, ethyl myristate, 2-hydroxysuccinic acid methyl ester, linoleic acid $(\geq 99 \%)$, linolenic acid, palmitoleic acid, phenethyl hexanoate $(\geq 97 \%)$, oleic acid ( $\geq 99 \%)$, tetradecane, and cis-vaccenic acid were obtained from Sigma-Aldrich (Sigma-Aldrich, St. Louis, USA). Ethyl trans-4-decenoate ( $>98 \%$ ) and cis-3-hexen-1-yl hexanoate (>98\%) were bought from TCI (TCI Germany, Eschborn, Germany).

\section{Sample Collection}

Ripe fruits of sea buckthorn (Hippophae rhamnoides), chokeberry (Aronia melanocarpa), wolfberry (Lycium barbarum), and European cornel (Cornus mas) were harvested at the "Landesforschungsanstalt für Landwirtschaft und Fischerei Mecklenburg-Vorpommern" in Gülzow-Prüzen Germany and stored at $-20^{\circ} \mathrm{C}$. We obtained berries of four varieties of sea buckthorn, namely Habego (HBG), Otradnaja (OTR), Trofimovskaja (TRO), and an unknown variety originated from the Alps (ALP). The chokeberries were all of the same type called Viking. The variety of the wolfberries is unknown. The European cornel belongs to the variety Albrechts Frühe. Samples of HBG were harvested in 2018; OTR, TRO, and ALP in 2017; chokeberry in 2017; and wolfberry and European cornel in 2015. The berries were transported to the laboratory using cooler boxes filled with ice. Samples were stored at $-18^{\circ} \mathrm{C}$ until further treatment.

\section{Sample Preparation}

After thoroughly washing with ultrapure water and removal of small leftover branches the fruits were freeze-dried for $48 \mathrm{~h}$ using the lab lyophilizer VaCo 2 (ZIRBUs technology, Bad Grund, Germany). To obtain a fine powder, the dried samples then were homogenized using the ANMER CG 8120 coffee grinder. Fruit powders were either extracted right after grinding or were stored at $-18^{\circ} \mathrm{C}$ until further use.

Liquid plant extracts were concentrated using a rotary evaporator and stored at $-18^{\circ} \mathrm{C}$. Right before their application in sublimation, the extracts were dried under reduced pressure $\left(10^{-3} \mathrm{mbar}\right)$ at $60^{\circ} \mathrm{C}$ for $1 \mathrm{~h}$ to prevent contamination of the cooling fingers through bubble formation.

\section{Extraction Procedures}

\section{Sublimation}

In a $250-\mathrm{mL}$ round bottom flask, $2 \mathrm{~g}$ of fruit powder was heated up to $90{ }^{\circ} \mathrm{C}$ using a heating plate with an oil bath. 
The flask was equipped with a cooling finger which was permanently cooled to $5{ }^{\circ} \mathrm{C}$. The pressure during the sublimation was always $<0.1 \mathrm{mbar}$. After $6 \mathrm{~h}$, the sublimation was stopped. Deposited material was rinsed from the cooling finger with $3 \mathrm{~mL}$ of methanol. The solutions were measured with a high-performance liquid chromatography-electrospray ionization-mass spectrometer system (HPLC-ESI-MS) and afterwards stored in the fridge. All powders were examined this way, and sublimations were done in triplicate.

Sublimation of the dried extracts was done in the same way but with a longer heating time of $24 \mathrm{~h}$ and lower oil bath temperature of $60^{\circ} \mathrm{C}$ to prevent decomposition.

\section{Ultrasound and Microwave Extraction (UME)}

$10 \mathrm{~g}$ of sea buckthorn (HBG) fruit powder were extracted three times with different solvents (Table 4) applying a solvent to solid ratio $(\mathrm{mL} / \mathrm{g})$ of $25: 1$. In the first step, the Teflon containers filled with sample and solvent were sonicated for 15 min using the ultrasound bath Sonorex Super RK 52 (Bandelin, Berlin, Germany). The fruit powder was then extracted three times at a defined temperature (Table 4) using the microwave Mars 240/50 (CEM Corporation, Matthews, USA). The second and third extraction steps were each performed with fresh solvent. The extraction time of microwave extraction was $10 \mathrm{~min}$ for each run at a microwave power of $800 \mathrm{MHz}$. Combined extracts were concentrated using a rotary evaporator and then stored at $-18^{\circ} \mathrm{C}$.

\section{HPLC-ESI-MS Analysis}

The analyses were carried out on an HPLC-ESI-MS system (UltiMate $^{\text {TM }}$ 3000, LTQ XL ${ }^{\mathrm{TM}}$ ) (Thermo Fisher Scientific, Dreieich, Germany). The data was processed with the Xcalibur ${ }^{\mathrm{TM}}$ Software (version 3.0.63) and visualized with OriginPro ${ }^{\circledR}$ 2020. Separations were performed on a Kinetex ${ }^{\circledR}$ Phenyl-Hexyl column $(150 \times 2.1 \mathrm{~mm}, 2.6 \mu \mathrm{m})$ at a controlled temperature of $35{ }^{\circ} \mathrm{C}$. The mobile phases consisted of methanol with $0.1 \%(\mathrm{v} / \mathrm{v})$ formic acid (eluent A) and water with $0.1 \%(\mathrm{v} / \mathrm{v})$ formic acid (eluent $\mathrm{B})$, using a gradient program as follows: $0 \mathrm{~min} 60 \% \mathrm{~B} ; 10 \mathrm{~min} 5 \% \mathrm{~B}$; $20 \min 5 \%$ B; $30 \min 20 \%$ B; $35 \min 60 \%$; $40 \min 60 \%$ B. The flow rate was $150 \mu \mathrm{L} / \mathrm{min}$ and the injection volume was $5 \mu \mathrm{L}$. Retention times (RT) are always given in minutes (min).

The MS was set up as follows: scan ESI negative (-); sweep gas flow: 10 arb. unit; auxiliary gas flow: 5 arb. unit; sheath gas flow: 35 arb. unit; $\mathrm{m} / \mathrm{z}$ range: $50-2000$; spray voltage: $-3.0 \mathrm{kV}$; capillary temperature $275^{\circ} \mathrm{C}$; capillary voltage: $-30.0 \mathrm{~V}$; tube lens voltage: $30 \mathrm{~V}$; H-ESI source heater: $300{ }^{\circ} \mathrm{C}$.

\section{Measurement of Reference Substances}

Reference substances used to identify the ingredients in the sublimates were measured on the LC/MS employing the same method as used for the sublimates. The standard substances were dissolved in methanol and measured at a concentration of $1 \mathrm{mg} / \mathrm{ml}$. The reference compounds were known ingredients of sea buckthorn berries, which had molecular masses consistent with the mass-charge rations found in the sea buckthorn powder sublimates.

\section{Validation of the Identification Method}

To verify the specificity of the identified maker substances, a blind test was performed. Four commercially available fruit powders were analyzed by sublimation. These were fruit powders of rose hip (Alpi Investment LTD, Sofia, Bulgaria), orange (Good Smoothie GmbH, BöhlIggelheim, Germany), mango (Bremer Gewürzhandel $\mathrm{GmbH}$, Bremen, Germany), and sea buckthorn (Fläminger Genussland GmbH, Niederer Fläming OT Reinsdorf, Germany). The samples were placed in four identical brown glass vials and referred to as samples one to four, so the investigator did not know which powder belonged to which fruit. They were then analyzed in the same way as the other fruit powders by sublimation. Only the composition of the sublimate was used to check whether the sea buckthorn berry could be identified by the previously determined marker substances.

\section{Results and Discussion}

We used sublimation to study dried fruit powders and dried extracts. For this purpose, we took advantage of the benefits of sublimation, namely products with increased purity, no solvent consumption, and fast sample preparation.

Firstly, the sublimates of different varieties of sea buckthorn were compared, and some relevant marker compounds were identified. Afterwards, sublimates of chokeberry, wolfberry, and European cornel were prepared, and the occurrence of the previously determined markers were checked. Finally, different extracts of the Habego (HBG) berry and its sublimates were compared and additional marker substances were detected (Fig. 1).

In the following, the MS results of the plants are only discussed for the negative scan mode. The positive scan mode shows similar but fewer peaks which can be attributed to compounds (see supporting information, Figure I). It is therefore not discussed further. All chromatograms are displayed in base peak mode. 


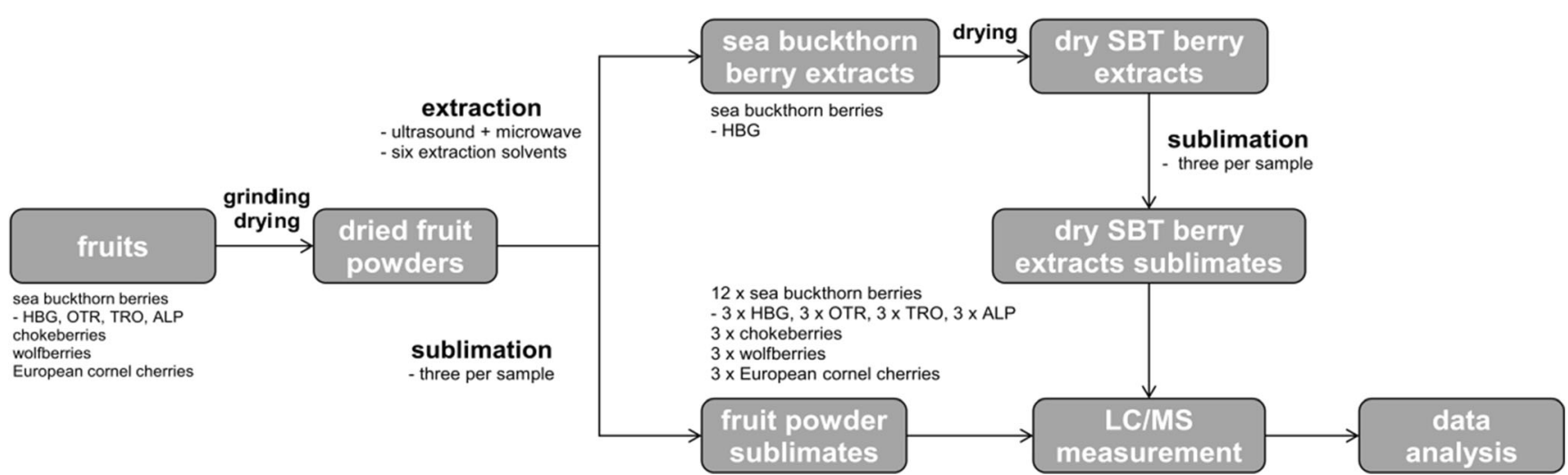

Fig. 1 Experimental design of the current study

\section{Fruit Powder Sublimation}

\section{Sea Buckthorn Powder Sublimation}

Since we had four different species of sea buckthorn berries available, we first subjected them to sublimation and compared the results (Fig. 2).

For each of the varieties we used, we were able to discover peculiarities in their composition that set them apart from the rest. Thus, we found specific masses in the varieties HBG, OTR, and ALP, which were exclusively found in their sublimates (examples in supporting information, Figures II-V). The TRO variety differed from the other varieties. Masses typical for the other species could not be detected here. The evaluation of the chromatograms ultimately results in a specific composition for each variety. In Table 1, all masses are listed which make a qualitative distinction between the four types of sea buckthorn possible. Of course, there are also overlaps between the species, but the proportions of certain substances in the plants vary. For example, three main peaks in each chromatogram appear at the time range from 17 to $19 \mathrm{~min}$ but they differ in peak height. The reason for this can be, in addition to the difference in the variety, varying harvest times, weather, and environmental influences. We can also see some small variation in intensity for the first eluting substances at a retention time of 2-3 min. Peaks between 12 and 16 min also show differences in their intensities but the variety of the Alps does not distinguish as much from the others as it may seem at first sight (see supporting information, Fig. VI).

\section{Identification of Marker Compounds in the Sublimates of Sea Buckthorn Berries}

Apart from the differences, we were particularly interested in the similarities between the sublimates. Is it possible to use sublimation to obtain certain markers from a plant to determine its identity independently of its specific variety? Table 2 compiles a list of compounds that could be found in the sublimates of all sea buckthorn berries examined in this study.
Fig. 2 Base peak chromatograms of sea buckthorn powder sublimates. The four investigated varieties Habego (HBG), Otradnaja (OTR), Trofimovskaja (TRO), and a variety form the Alps (ALP) show a similar peak pattern. The Normalization Level (NL) indicates the intensity of the largest peak for each chromatogram

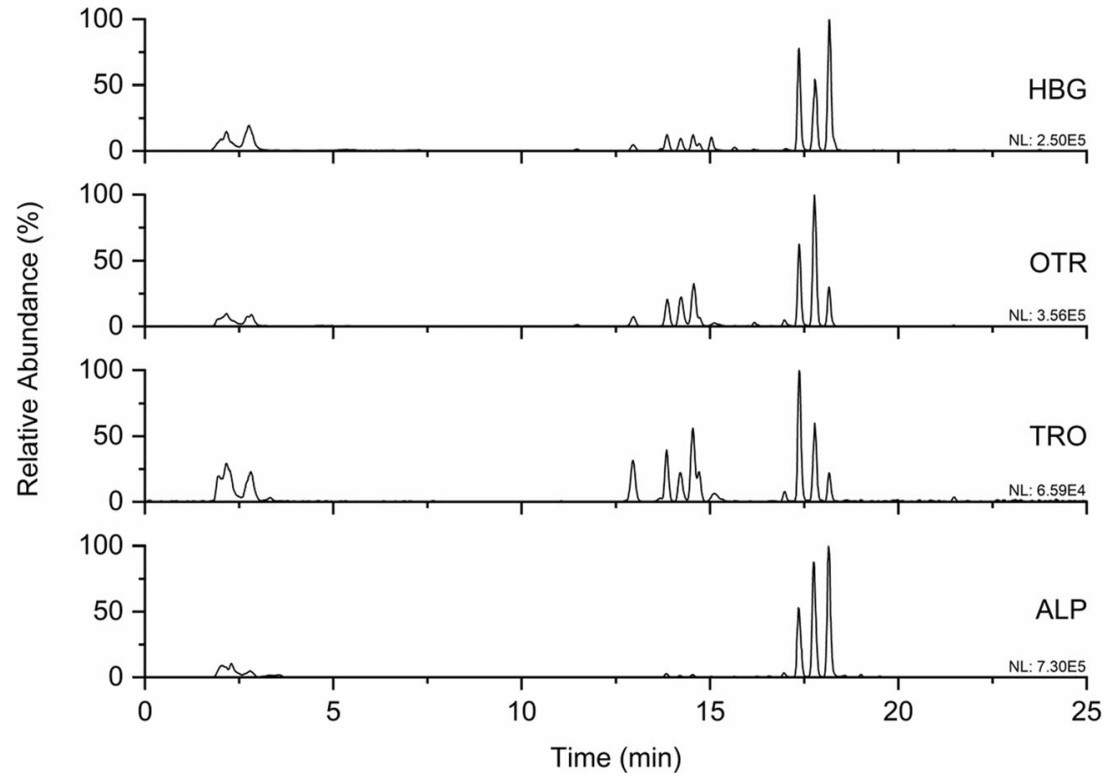


Table 1 Specific mass-to-charge ratios $(\mathrm{m} / \mathrm{z})$ that were found in the chromatograms of the sea buckthorn sublimates of HBG, OTR, and ALP. Some masses that occur to all these varieties are not detected (n.d.) in the chromatogram of the sea buckthorn sublimate of TRO

\begin{tabular}{llllll}
\hline HBG & & & & \\
\cline { 5 - 6 } RT (min) & $m / z$ & & RT (min) & & $m / z$ \\
\hline 2.8 & 413 & 2.8 & n.d. & 577 \\
5.5 & 119 & 4.6 & n.d. & 232 \\
5.5 & 165 & 4.6 & n.d. & 300 \\
OTR & & 4.6 & n.d. & 362 \\
RT (min) & $m / z$ & 7.2 & n.d. & 203 \\
15.2 & 368 & 16.2 & n.d. & 297 \\
15.2 & 383 & 16.2 & n.d. & 333 \\
15.2 & 384 & 17.0 & n.d. & 225 \\
ALP & & 17.0 & n.d. & 227 \\
RT (min) & $m / z$ & 25.7 & n.d. & 423 \\
16.6 & 223 & & & \\
16.6 & 337 & & & \\
19.5 & 311 & & & \\
\hline
\end{tabular}

After qualitative analysis of chromatograms and associated mass spectra, these substances were defined as marker compounds that generally appear in berry sublimates of sea buckthorn. This assumption is supported by the fact that four varieties of sea buckthorn berries were investigated which were harvested in 2017 and 2018. Prerequisite for the inclusion of the substances in Table 2 was the detection limit being exceeded in each of the twelve sublimates (three sublimations per variety) obtained from the fruit powders. According to the guidelines of the ICH (International Conference on Harmonization), this was checked by visual evaluation (Shrivastava and Gupta 2011).

Some of the natural compounds found in the sublimates of sea buckthorn were identified by comparing the MS fragments with literature data and then performing measurements of reference substances. These are primary metabolites, which can be found in most plants. Among them are small organic acids like malic acid as well as fatty acids like palmitic acid. However, most of the masses found in the sublimates of the sea buckthorn varieties were not described in literature before. Therefore, it can be assumed that these are as yet unknown secondary plant constituents of sea buckthorn. This discovery is interesting for several reasons, since we hereby showed that sublimation can be used to obtain previously unknown natural substances from plant materials.

\section{Chokeberry, Wolfberry, European Cornel Powder Sublimation}

To determine whether or not these markers were specific for sea buckthorn, we compared all of them to the sublimates of chokeberry, wolfberry, and European cornel powders. Even a brief look at the chromatograms of the various sublimates shows that there are some differences in their composition (Fig. 3).

At early retention times (2-4 min), it is noticeable that the wolfberry shows only a very small peak here. The other fruits display similar peaks in this range only sea buckthorn having an additional peak at RT $2.8 \mathrm{~min}$. A comparison of the mass spectra in this poorly resolved part of the chromatogram reinforces the first impression when looking at the graphs. The European cornel, which has the largest peak area in common with the sea buckthorn, also displays many of the same masses in this area. The chokeberry also shows a great similarity with the sea buckthorn. Only the wolfberry differs quite strongly from the latter already in this range (Table 3 ). The greatest similarity with sea buckthorn is shown by the European cornel which shows 20 of the 52 markers of the sea buckthorn. This is followed by the chokeberry with 18 and the wolfberry with 16 matches. In total, 27 specific markers remain for the sea buckthorn (Table 2). Each of the plant sublimates has specific peaks in its chromatogram that do not occur in the others. In the chromatogram of the wolfberry, these are found at about 5 and $20 \mathrm{~min}$, in the case of the European cornel at $8 \mathrm{~min}$, in the case of the chokeberry at $9 \mathrm{~min}$, and in the case of the sea buckthorn at 10-15 min. The comparison of the MS spectra shows no further matches between the sea buckthorn and the other plant sublimates up to minute 17 . The main components of all sublimates are different fatty acids, which were detected in the range between minute 17 and 19. The amount differs depending on the plant and, for example, palmitoleic acid could only be detected in the sea buckthorn and the wolfberry.

After the chromatograms and MS spectra of the sublimates were compared with each other, the results suggest that the initial question can be answered. The direct sublimation of substances from dried plant material makes it possible to obtain marker compounds to determine the identity of a plant. This result shows that direct sublimation can be used as an additional method to combat food fraud.

\section{Validation of the Identification Method}

In order to verify whether the specific marker substances can really be used to identify the sea buckthorn berry, four additional fruit powders were commercially acquired. These were the fruit powders of sea buckthorn, rose hip, pineapple, and orange. The powders were selected according to their visual similarity to sea buckthorn powder and presented to the investigator as powders one to four. The ingredients of the sublimates of the powders were compared with the marker substances of the sea buckthorn berry sublimates and the correspondence was checked (Table 4).

It can easily be seen that powder four had the highest similarity in the composition of its sublimate with that of the sea buckthorn berry sublimates. Nearly $80 \%$ of the marker 
Table 2 Marker compounds that were found in every sublimate of each sea buckthorn powder investigated. Most of the substances could not be identified (n.i.) after comparison of $\mathrm{m} / \mathrm{z}$ values with literature data and measured reference substances. 27 (*) of these markers were found to be specific for the sea buckthorn after comparison with other fruit sublimates

\begin{tabular}{llllll}
\hline ID & RT (min) & Structure assignment & Molar mass $(\mathrm{g} / \mathrm{mol})$ & $m / z$ & References \\
\hline 1 & 2.0 & Fumaric acid & 116.07 & 115 & \\
2 & 2.0 & Malic acid & 134.09 & 133 & (Tiitinen et al. 2006) \\
3 & 2.0 & (+)-Catechin & 290.27 & 289 & (Rösch et al. 2003;
\end{tabular}

Määttä-Riihinen et al. 2004

Olas et al. 2018)

333

158

159

175

186

245

291

231

298

327

163

203

289

129

179

381

171

218

246

218

233

188

217

232

260

275

216

244

259

246

274

289

219

230

245

197

265

327

381

Hexadecadienoic acid $252.39 \quad 251$

(Teleszko et al. 2015)

271

319

277

253
(Dulf 2012; Teleszko et al. 2015)

(Teleszko et al. 2015; Dulf 2012; Schiller 1989; Cakir 2004; 
Table 2 (continued)

\begin{tabular}{|c|c|c|c|c|c|}
\hline ID & $\mathrm{RT}(\min )$ & Structure assignment & Molar mass $(\mathrm{g} / \mathrm{mol})$ & $m / z$ & References \\
\hline & & & & & Ercisli et al. 2007) \\
\hline 48 & 17.8 & Palmitic acid & 256.43 & 255 & $\begin{array}{l}\text { (Teleszko et al. 2015; Dulf 2012; } \\
\text { Schiller 1989; Cakir 2004; } \\
\text { Ercisli et al. 2007; Hirvi and } \\
\text { Honkanen 1984) }\end{array}$ \\
\hline 49 & 17.8 & Linoleic acid & 280.45 & 279 & $\begin{array}{l}\text { (Teleszko et al. 2015; Dulf 2012; } \\
\text { Cakir 2004; } \\
\text { Ercisli et al. 2007) }\end{array}$ \\
\hline 50 & 18.2 & $c i s$-vaccenic acid & 282.46 & 281 & $\begin{array}{l}\text { (Teleszko et al. 2015; Dulf 2012; } \\
\text { Schiller 1989; Cakir 2004; } \\
\text { Ercisli et al. 2007) }\end{array}$ \\
\hline 51 & 18.2 & n.i. & & 349 & \\
\hline 52 & 18.2 & n.i. & & 586 & \\
\hline
\end{tabular}

substances could be found here whereas only $38 \%, 33 \%$, and $17 \%$ were detected in powder two, three, and one (see supporting information, Table III). If only the specific marker compounds are considered the results become even more evident. Powders two and three show none of the specific markers in their sublimates and powder one only one. $74 \%$ of the specific marker substances were found in the fourth fruit powder, only $5 \%$ less than the overall match. The results clearly indicate that powder number four is the sea buckthorn powder. This was confirmed after consultation with the person who filled the samples. Thus, it could be shown that the identification of plant powders using marker substances from sublimates is possible. The differences in composition between the commercially acquired sea buckthorn berry powder and the self-produced powder are probably due to different growing areas. Furthermore, the commercial powders were not stored permanently at $-18^{\circ} \mathrm{C}$.

\section{Sea Buckthorn Extracts}

Plant components are often extracted before further processing. Sea buckthorn, for example, can be found in many creams, ointments, and other cosmetic articles which require different types of plant extract for their production (Frede 2006). For this reason, various extracts of sea buckthorn berries (HBG) were subjected to sublimation. Solvents of different polarities, namely water, methanol, 1-butanol, ethyl acetate, trichloromethane, and toluene were chosen for the extraction (Table 5).

As expected, the compositions of the extracts were different. This can be seen from both the dry weights and the chromatograms of the extracts (Fig. 4).

More polar solvents such as water and methanol dissolve substances like small organic acids, flavonoids, sugars, and their combinations much better. As these compounds are
Fig. 3 Base peak chromatograms of the different fruit powder sublimates

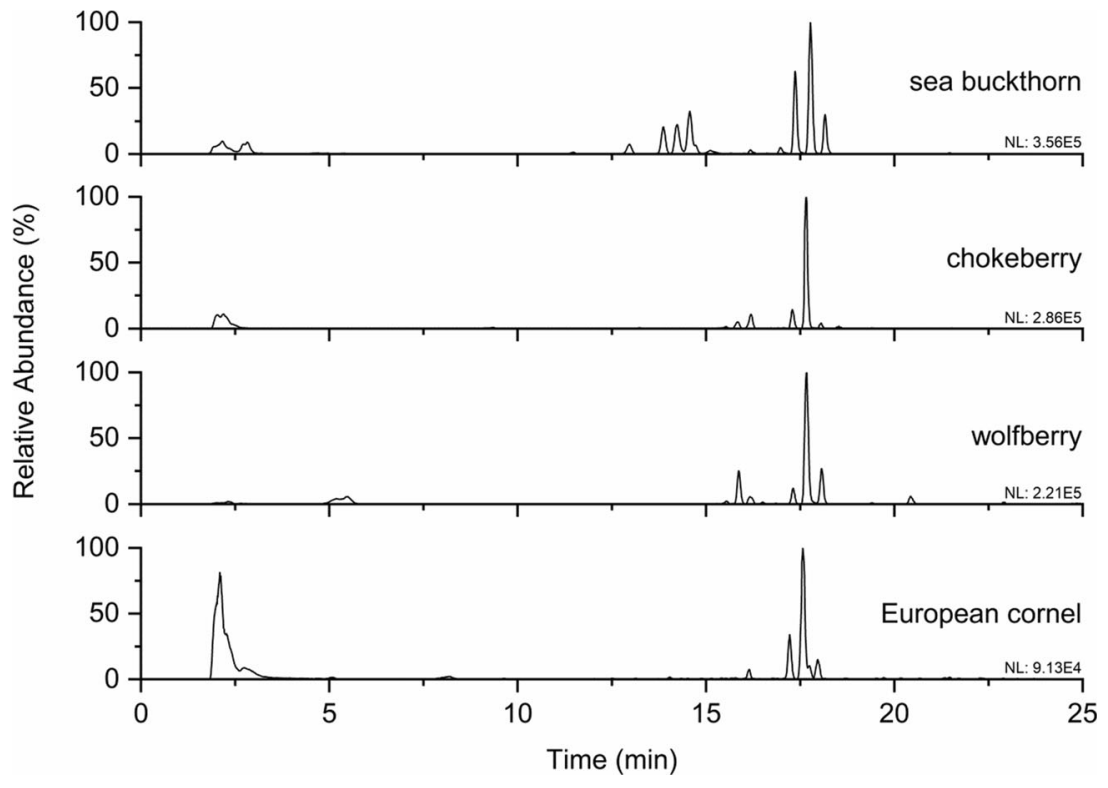


Table 3 Marker substances of sea buckthorn that are present (x) in chokeberry, wolfberry, and European cornel

\begin{tabular}{|c|c|c|c|c|}
\hline $\mathrm{RT}(\min )$ & $m / z$ & Aronia & Wolfberry & European cornel \\
\hline 2.0 & 115 & $\mathrm{x}$ & & $\mathrm{x}$ \\
\hline 2.0 & 133 & $\mathrm{x}$ & $\mathrm{x}$ & $\mathrm{x}$ \\
\hline 2.0 & 289 & $\mathrm{x}$ & & $\mathrm{x}$ \\
\hline 2.0 & 333 & $\mathrm{x}$ & & $\mathrm{x}$ \\
\hline 2.1 & 291 & & & $\mathrm{x}$ \\
\hline 2.1 & 158 & $\mathrm{x}$ & & $\mathrm{x}$ \\
\hline 2.1 & 159 & $\mathrm{x}$ & & $\mathrm{x}$ \\
\hline 2.1 & 186 & $\mathrm{x}$ & $\mathrm{x}$ & $\mathrm{x}$ \\
\hline 2.1 & 245 & $\mathrm{x}$ & $\mathrm{x}$ & $\mathrm{x}$ \\
\hline 2.2 & 231 & $\mathrm{x}$ & $\mathrm{x}$ & $\mathrm{x}$ \\
\hline 2.2 & 298 & $\mathrm{x}$ & & $\mathrm{x}$ \\
\hline 2.2 & 327 & $\mathrm{x}$ & & $\mathrm{x}$ \\
\hline 2.3 & 163 & & $\mathrm{x}$ & $\mathrm{x}$ \\
\hline 2.3 & 203 & & $\mathrm{x}$ & \\
\hline 2.3 & 289 & $\mathrm{x}$ & & $\mathrm{x}$ \\
\hline 2.4 & 129 & & $\mathrm{x}$ & $\mathrm{x}$ \\
\hline 2.8 & 381 & & $\mathrm{x}$ & \\
\hline 17.0 & 251 & & $\mathrm{x}$ & \\
\hline 17.4 & 277 & $\mathrm{x}$ & $\mathrm{x}$ & $\mathrm{x}$ \\
\hline 17.4 & 253 & & $\mathrm{x}$ & \\
\hline 17.8 & 255 & $\mathrm{x}$ & $\mathrm{x}$ & $\mathrm{x}$ \\
\hline 17.8 & 279 & $\mathrm{x}$ & $\mathrm{x}$ & $\mathrm{x}$ \\
\hline 18.2 & 281 & $\mathrm{x}$ & $\mathrm{x}$ & $\mathrm{x}$ \\
\hline 18.2 & 349 & $\mathrm{x}$ & $\mathrm{x}$ & $\mathrm{x}$ \\
\hline 18.2 & 586 & $\mathrm{x}$ & $\mathrm{x}$ & \\
\hline \multicolumn{5}{|c|}{$\mathrm{x}$, present in sublimate } \\
\hline
\end{tabular}

present in the sea buckthorn to a high degree, these extracts thus have the highest dry weights. The chromatograms of the non-polar extracts show stronger peaks in the range of 10 $30 \mathrm{~min}$. In this range, there are mainly peaks from phytosterols, fatty acids, and carotenoids. Besides the obvious differences between polar and non-polar extracts, there are signals in each extract that do not occur in the others. These, in

Table 4 Conformity of sublimates of commercially purchased fruit powders with all (total) or specific (*) previously determined marker substances of the sea buckthorn berry

\begin{tabular}{|c|c|c|c|c|}
\hline & \multicolumn{4}{|c|}{ Fruit powder } \\
\hline & 1 & 2 & 3 & 4 \\
\hline \multirow{2}{*}{$\begin{array}{l}\text { Matching compounds } \\
\text { (total) }\end{array}$} & 9 & 20 & 17 & 41 \\
\hline & $(17 \%)$ & $(38 \%)$ & $(33 \%)$ & $(79 \%)$ \\
\hline \multirow{2}{*}{$\begin{array}{l}\text { Matching compounds } \\
\quad(*)\end{array}$} & 1 & 0 & 0 & 20 \\
\hline & $(4 \%)$ & $(0 \%)$ & $(0 \%)$ & $(74 \%)$ \\
\hline
\end{tabular}

Table 5 Extraction solvents, temperature, and dry weights of sea buckthorn (HBG) extracts prepared by ultrasound and microwave extraction (UME). The weight was $10 \mathrm{~g}$ sea buckthorn powder for each extraction. Extraction temperatures varied due to different boiling points

\begin{tabular}{lll}
\hline Extraction solvent & Dry weight $(\mathrm{g})$ & Extraction temperature $\left({ }^{\circ} \mathrm{C}\right)$ \\
\hline Water & 5.1 & 80 \\
Methanol & 5.1 & 60 \\
1-Butanol & 4.6 & 80 \\
Ethyl acetate & 2.9 & 60 \\
Trichloromethane & 2.8 & 60 \\
Toluene & 2.8 & 80 \\
\hline
\end{tabular}

combination with all other substances found in the extracts, provide a unique fingerprint for the plant extracts.

\section{Sublimates of Sea Buckthorn Extracts}

With this aspect in mind, the dry extracts were used in sublimation. Since the choice of solvent determines the composition of the extracts, it is not surprising that the chromatograms of the sublimates also differ (Fig. 5).

Each sublimate contains fewer peaks in the chromatogram compared to the dry extract. Since many substances cannot be sublimated due to their low vapor pressures, this was to be expected. For example, the sublimates lack any sugar compounds and a high amount of non-polar substances which appear in the chromatograms of the less polar extracts in the range of 10-30 min. Fatty acids, on the other hand, are the main components in the sublimates of organic solvent extracts and show the largest peaks in the range of 17-19 $\mathrm{min}$. In the extracts, they are hardly noticeable apart from the larger signals of other compounds (see supporting information, Figure VII). The higher purity is particularly useful when substances are to be isolated from the sublimates. The comparatively small number of compounds makes chromatographic separation of the ingredients easier. At the same time, it is still possible to distinguish each of the sublimates. Mass spectra of the respective chromatograms were examined and thus separate marker substances could be defined for each extract sublimate (see supporting information, Table IV). Of particular interest in this context are the compounds that occur in only one of the sublimates. These can be divided into two groups. The first group consists of compounds that can also be detected in the dry extracts. Accordingly, these serve as marker substances for both the sublimates and the extracts. When extracting sea buckthorn with alcohols, for example, malic acid esters are formed. These esters are present in both the sublimate (Fig. 6) and the extract. This ester formation is helpful on the one hand because it helps to identify these extracts. On the other hand, a general disadvantage of the extraction 
Fig. 4 Base peak chromatograms of sea buckthorn (HBG) extracts

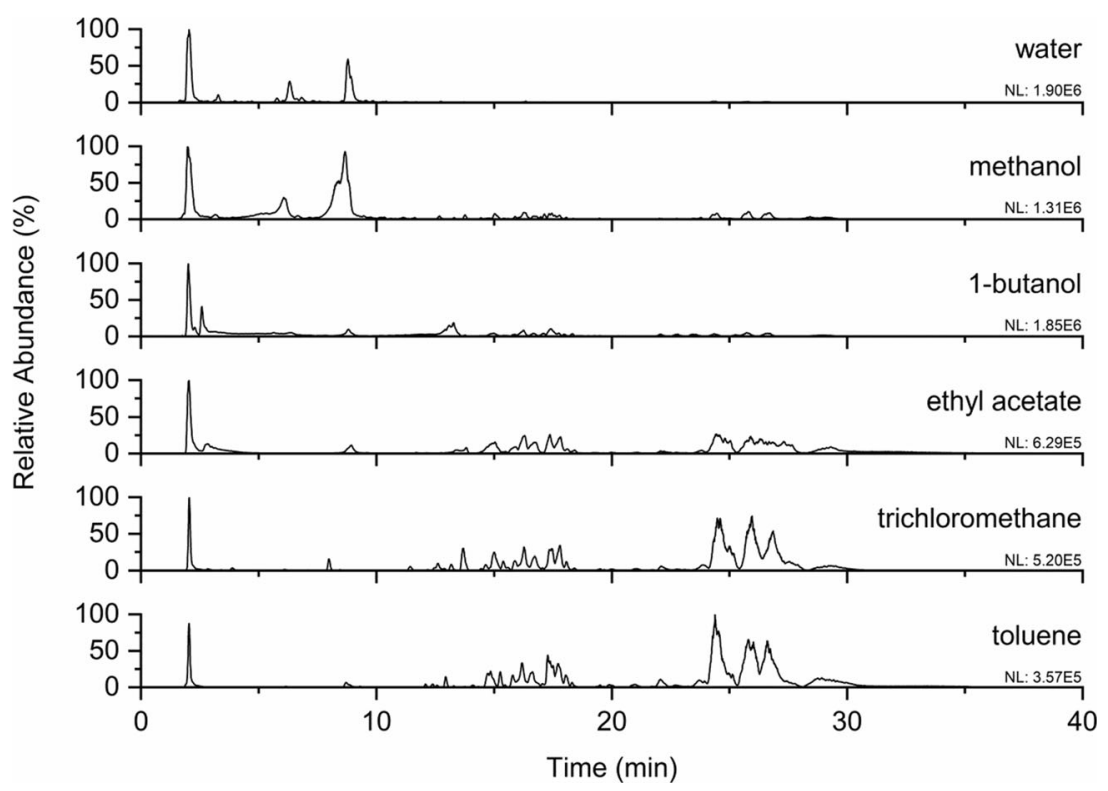

process can be seen, because the reaction with solvents changes ingredients.

Marker compounds that appear in the extracts as well as in the sublimates of the extracts were found for all solvents, except water (Table 6).

However, most of the marker substances found in the sublimates of the dry extracts could not be detected in the extracts (Table 7). This may be due to several reasons. Firstly, the concentration of some compounds in the extracts is so low that they cannot be detected by MS. Through sublimation, these compounds can be enriched at the cooling finger whereas many other substances remain in the extract. Since the cooling finger was rinsed with only a small amount of solvent, the concentration of the sublimated substances was relatively high and detection became possible. Another reason could be explained by the low thermodynamic stability of some ingredients of the sea buckthorn. The applied heat and the high vacuum could cause these substances to decompose, and the products of these processes could be deposited on the cooling finger. Irrespective of which case applies, these and most of the other compounds obtained by sublimation from the dry extracts are of great interest. Firstly, due to the unique composition of the sublimates, it is possible to infer the extraction agent with which they were originally extracted. This would allow certain products in the food industry to be checked for authenticity. On the other hand, many of the substances we found in the sublimates of the dry extracts are not known in literature. Thus, sublimation offers us the possibility of
Fig. 5 Base peak chromatograms of sea buckthorn (HBG) extracts sublimates

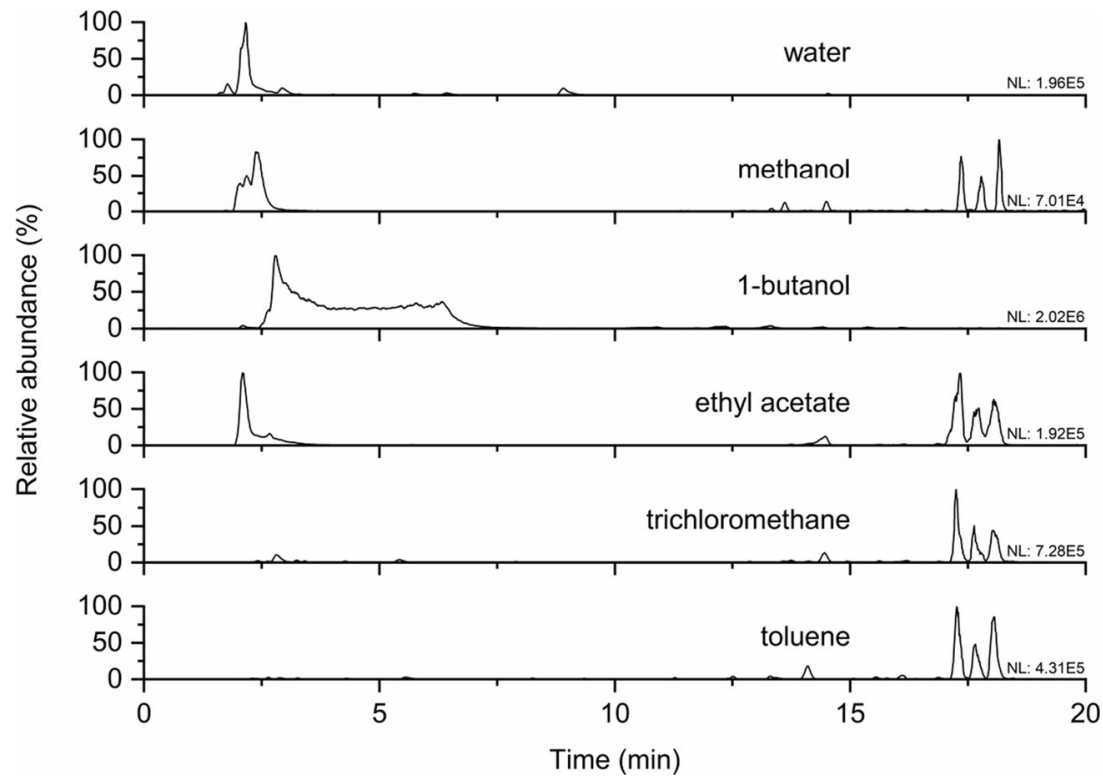


Fig. 6 Mass range chromatograms $(\mathrm{m} / \mathrm{z}, 147$ for methanol, $m / z, 189$ for butanol) and corresponding MS spectra of formed malic acid esters

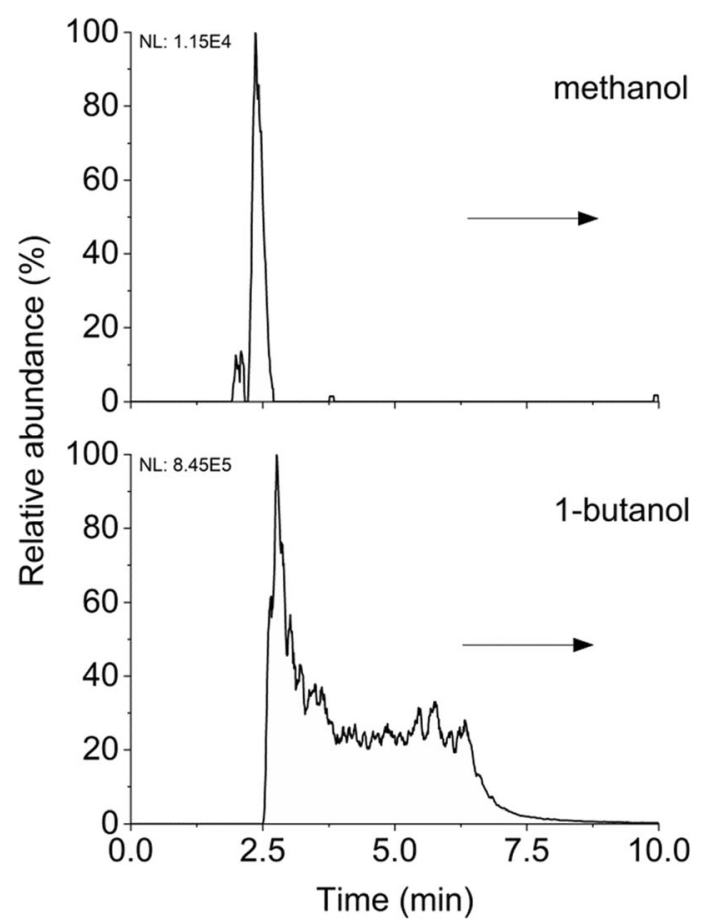

enriching and discovering still unknown compounds also from extracts.

After performing sublimation with both dry plant powder and dried plant extracts, the advantages of this approach are obvious. Sublimation from the powder requires less preparation and fewer steps, uses no solvent except for rinsing the cold traps, and therefore produces hardly any waste. The sublimates also have a higher purity, which will make it easier to isolate new substances from them. In contrast, sublimation

Table 6 Marker compounds that were found in dry extracts and their sublimates

\begin{tabular}{|c|c|c|c|c|c|}
\hline \multicolumn{2}{|l|}{ Methanol } & \multicolumn{2}{|c|}{ Ethyl acetate } & \multicolumn{2}{|l|}{ Toluene } \\
\hline RT (min) & $m / z$ & $\mathrm{RT}$ (min) & $m / z$ & $\mathrm{RT}(\min )$ & $\mathrm{m} / \mathrm{z}$ \\
\hline \multirow[t]{2}{*}{2.4} & 147 & 2.2 & 271 & 2.3 & 173 \\
\hline & & 2.6 & 289 & 2.4 & 259 \\
\hline 1-Butanol & & \multicolumn{2}{|c|}{ Trichloromethane } & 9.3 & 204 \\
\hline RT (min) & $m / z$ & $\mathrm{RT}(\min )$ & $m / z$ & 9.3 & 219 \\
\hline 2.6 & 186 & 2.4 & 195 & 9.3 & 331 \\
\hline \multirow[t]{8}{*}{2.8} & 127 & 3.5 & 161 & 11.2 & 231 \\
\hline & & 5.4 & 385 & 11.2 & 249 \\
\hline & & 8.5 & 219 & 11.8 & 248 \\
\hline & & & & 12.3 & 287 \\
\hline & & & & 15.6 & 271 \\
\hline & & & & 15.8 & 295 \\
\hline & & & & 16.2 & 365 \\
\hline & & & & 16.9 & 269 \\
\hline
\end{tabular}

from the extracts has the advantage that the ingredients in the extract are enriched and thus a larger quantity of

Table 7 Marker compounds of the dry extracts sublimates which did not appear in the extracts. Sublimates of extracts of non-polar solvents like toluene and trichloromethane show the highest number of possibly not yet described substances for sea buckthorn

\begin{tabular}{|c|c|c|c|c|c|c|c|}
\hline \multicolumn{2}{|l|}{ Water } & \multicolumn{2}{|c|}{ Ethyl acetate } & \multicolumn{4}{|l|}{ Toluene } \\
\hline $\mathrm{RT}(\min )$ & $\mathrm{m} / \mathrm{z}$ & $\mathrm{RT}(\min )$ & $m / z$ & $\mathrm{RT}(\min )$ & $m / z$ & $\mathrm{RT}(\mathrm{min})$ & $m / z$ \\
\hline 2.3 & 163 & 2.7 & 367 & 2.4 & 197 & 7.9 & 313 \\
\hline 2.8 & 247 & 5.7 & 401 & 2.6 & 111 & 10.5 & 120 \\
\hline \multicolumn{2}{|l|}{ Methanol } & \multicolumn{2}{|c|}{ Trichloromethane } & 2.6 & 161 & 10.5 & 164 \\
\hline $\mathrm{RT}(\min )$ & $m / z$ & $\mathrm{RT}(\min )$ & $m / z$ & 2.6 & 523 & 10.5 & 192 \\
\hline 13.3 & 221 & 2.3 & 273 & 2.8 & 225 & 10.8 & 219 \\
\hline 13.3 & 236 & 2.8 & 289 & 3.0 & 225 & 10.8 & 262 \\
\hline 13.3 & 293 & 2.8 & 413 & 3.3 & 239 & 10.8 & 277 \\
\hline 13.3 & 361 & 3.3 & 275 & 3.3 & 301 & 11.2 & 216 \\
\hline 1-Butanol & & 5.2 & 271 & 3.3 & 316 & 12.2 & 202 \\
\hline RT (min) & $\mathrm{m} / \mathrm{z}$ & 8.8 & 192 & 3.7 & 235 & 12.2 & 230 \\
\hline 16.1 & 331 & 12.5 & 189 & 3.7 & 297 & 12.2 & 258 \\
\hline \multirow[t]{8}{*}{16.1} & 399 & 12.5 & 259 & 3.9 & 267 & 12.2 & 273 \\
\hline & & 12.5 & 351 & 5.0 & 119 & 12.3 & 232 \\
\hline & & 13.9 & 189 & 5.4 & 221 & 12.9 & 202 \\
\hline & & 13.9 & 259 & 5.4 & 233 & 12.9 & 230 \\
\hline & & 13.9 & 351 & 5.4 & 295 & 12.9 & 258 \\
\hline & & 15.6 & 245 & 6.5 & 132 & 12.9 & 273 \\
\hline & & & & 6.6 & 144 & 15.6 & 285 \\
\hline & & & & 7.9 & 251 & & \\
\hline
\end{tabular}


substances is available for sublimation. As a result, the sublimates of the extracts contain more substances. The choice of solvent can also be used to control in advance what kind of compounds the sublimate will contain.

\section{Conclusions}

These results show that sublimation is a very promising addition to the more commonly used extraction methods. We were able to define 52 marker compounds which appear in the sublimates of sea buckthorn fruit powders. Even more marker compounds were determined for the sublimates of different sea buckthorn extracts. Compared with three other fruit powder sublimates, the sea buckthorn still shows 27 specific markers. Specific marker substances were also found in each of the sublimates of the dry extracts. Some of them were also present in the extracts, but most were occurring exclusively in the sublimates. Particularly interesting in both cases is that most of the sublimated compounds were not described in literature concerning sea buckthorn before. In this sense, sublimation thus offers a completely new possibility for identifying previously unknown plant constituents. To the best of our knowledge, we are the first to show that sublimation is a tool to identify plants and their extracts, so it could be utilized in the detection of food fraud. More research is needed in this field of analytical chemistry, and in the next step, sublimation on different plant materials could be studied. Also, a scale-up of the sublimation would be of interest so structures that remain unknown until now can be identified.

Supplementary Information The online version contains supplementary material available at https://doi.org/10.1007/s12161-020-01954-6.

Acknowledgments Open Access funding enabled and organized by Projekt DEAL. We would like to thank Dr. Frank Hippauf from the "Landesforschungsanstalt für Landwirtschaft und Fischerei Mecklenburg-Vorpommern" for providing the plant material and for his continuing support. We would also like to thank Mrs. Sandra Diederich for her excellent support in the lab.

Authors' Contributions All authors contributed to the study conception and design. Material preparation, data collection, and analysis were performed by Manuel Gronbach and Laura Kraußer. The first draft of the manuscript was written by Manuel Gronbach, and all authors commented on previous versions of the manuscript. All authors read and approved the final manuscript.

Funding This work was supported by the European Union (PePPP center of excellence MV: grant ESF/14-BM-A55-0048/16). The LTQ XL LC/ MS system was co-financed by the European Union from the European Regional Development Fund GHS-17-0034 under the Operational Program Mecklenburg-Vorpommern 2014-2020-Investments in growth and employment.
Data Availability The data that support the findings of this study are available from the corresponding author, U. Kragl, upon reasonable request.

\section{Compliance with Ethical Standards}

Conflict of Interest Manuel Gronbach declares that he has no conflict of interest. Laura Kraußer declares that she has no conflict of interest. Timo Broese declares that he has no conflict of interest. Christina Oppermann declares that she has no conflict of interest. Udo Kragl declares that he has no conflict of interest.

Ethical Approval Not applicable.

Informed Consent Informed consent not applicable.

Code Availability Not applicable.

Open Access This article is licensed under a Creative Commons Attribution 4.0 International License, which permits use, sharing, adaptation, distribution and reproduction in any medium or format, as long as you give appropriate credit to the original author(s) and the source, provide a link to the Creative Commons licence, and indicate if changes were made. The images or other third party material in this article are included in the article's Creative Commons licence, unless indicated otherwise in a credit line to the material. If material is not included in the article's Creative Commons licence and your intended use is not permitted by statutory regulation or exceeds the permitted use, you will need to obtain permission directly from the copyright holder. To view a copy of this licence, visit http://creativecommons.org/licenses/by/4.0/.

\section{References}

Aoyagi N, Kimura R, Murata T (1974) Studies on passiflora incarnata dry extract. I Isolation of maltol and pharmacological action of maltol and ethyl maltol. Chem Pharm Bull 22:1008-1013. https://doi.org/ 10.1248/cpb.22.1008

Arvindekar AU, Pereira GR, Laddha KS (2015) Assessment of conventional and novel extraction techniques on extraction efficiency of five anthraquinones from Rheum emodi. J Food Sci Technol 52: 6574-6582. https://doi.org/10.1007/s13197-015-1814-3

Bucar F, Wube A, Schmid M (2013) Natural product isolation - how to get from biological material to pure compounds. Nat Prod Rep 30: 525-545. https://doi.org/10.1039/c3np20106f

Burnett AR, Thomson RH (1967) Naturally occurring quinones. Part X. The quinonoid constituents of Tabebuia avellanedae (Bignoniaceae). J Chem Soc C 2100. https://doi.org/10.1039/ J39670002100

Cakir A (2004) Essential oil and fatty acid composition of the fruits of Hippophae rhamnoides L. (Sea Buckthorn) and Myrtus communis L. from Turkey. Biochem Syst Ecol 32:809-816. https://doi.org/10. 1016/j.bse.2003.11.010

Dulf FV (2012) Fatty acids in berry lipids of six sea buckthorn (Hippophae rhamnoides L., subspecies carpatica) cultivars grown in Romania. Chem Cent J 6:106. https://doi.org/10.1186/1752153X-6-106

Ercisli S, Orhan E, Ozdemir O, Sengul M (2007) The genotypic effects on the chemical composition and antioxidant activity of sea buckthorn (Hippophae rhamnoides L.) berries grown in Turkey. Sci HorticAmsterdam 115:27-33. https://doi.org/10.1016/j.scienta.2007.07. 004 
Frede W (2006) Taschenbuch für Lebensmittelchemiker; Lebensmittel Bedarfsgegenstände - Kosmetika - Futtermittel, German edn. Springer, Dordrecht

Glavin DP, Cleaves HJ, Buch A, Schubert M, Aubrey A, Bada JL, Mahaffy PR (2006) Sublimation extraction coupled with gas chromatography-mass spectrometry: a new technique for future in situ analyses of purines and pyrimidines on Mars. Planet Space Sci 54:1584-1591. https://doi.org/10.1016/j.pss.2005.12.023

Guidoin M-F, Yang J, Pichette A, Roy C (2003) Betulin isolation from birch bark by vacuum and atmospheric sublimation. A thermogravimetric study. Thermochim Acta 398:153-166. https://doi.org/10. 1016/S0040-6031(02)00358-1

Gurib-Fakim A (2006) Medicinal plants: traditions of yesterday and drugs of tomorrow. Mol Asp Med 27:1-93. https://doi.org/10. 1016/j.mam.2005.07.008

Hargreaves KR, Carnduff J, Nechvatal A (1968) Root-bark constituents of Hypericum elatum and H. androsaemum. Phytochemistry 7:331. https://doi.org/10.1016/S0031-9422(00)86333-5

Hirvi T, Honkanen E (1984) The aroma of the fruit of sea Buckthorn, Hippophae rhamnoides, L. Z Lebensm Unters For 179:387-388. https://doi.org/10.1007/BF01043436

Hong E, Lee SY, Jeong JY, Park JM, Kim BH, Kwon K, Chun HS (2017) Modern analytical methods for the detection of food fraud and adulteration by food category. J Sci Food Agric 97:3877-3896. https:// doi.org/10.1002/jsfa.8364

Kassing M, Jenelten U, Schenk J, Strube J (2010) A new approach for process development of plant-based extraction processes. Chem Eng Technol 33:377-387. https://doi.org/10.1002/ceat.200900480

Kosuge T, Kamiya H (1962) Discovery of a pyrazine in a natural product: tetramethylpyrazine from cultures of a strain of Bacillus subtilis. Nature 193:776. https://doi.org/10.1038/193776a0

Kuzma M, Jegorov A, Kacer P, Havlícek V (2001) Sequencing of new beauverolides by high-performance liquid chromatography and mass spectrometry. J Mass Spectrom 36:1108-1115. https://doi. org/10.1002/jms.213

Lin C-H, Lin H-W, Wu J-Y, Houng J-Y, Wan H-P, Yang T-Y, Liang M$\mathrm{T}$ (2015) Extraction of lignans from the seed of Schisandra chinensis by supercritical fluid extraction and subsequent separation by supercritical fluid simulated moving bed. J Supercrit Fluid 98:17-24. https://doi.org/10.1016/j.supflu.2014.12.025

Määttä-Riihinen KR, Kamal-Eldin A, Mattila PH, González-Paramás AM, Törrönen AR (2004) Distribution and contents of phenolic compounds in eighteen Scandinavian berry species. J Agric Food Chem 52:4477-4486. https://doi.org/10.1021/jf049595y

Matz G (1966) Die Sublimation im Rahmen der thermischen Trennverfahren. Chem Ing Technol 38:299-308. https://doi.org/ 10.1002/cite.330380322

Newman DJ, Cragg GM (2016) Natural products as sources of new drugs from 1981 to 2014. J Nat Prod 79:629-661. https://doi.org/10.1021/ acs.jnatprod.5b01055

Olas B, Żuchowski J, Lis B, Skalski B, Kontek B, Grabarczyk Ł, Stochmal A (2018) Comparative chemical composition, antioxidant and anticoagulant properties of phenolic fraction (a rich in nonacylated and acylated flavonoids and non-polar compounds) and non-polar fraction from Elaeagnus rhamnoides (L.) A. Nelson fruits. Food Chem 247:39-45. https://doi.org/10.1016/j.foodchem.2017. 12.010

Rösch D, Bergmann M, Knorr D, Kroh LW (2003) Structure-antioxidant efficiency relationships of phenolic compounds and their contribution to the antioxidant activity of sea buckthorn juice. J Agric Food Chem 51:4233-4239. https://doi.org/10.1021/jf0300339

Schiller H (1989) Fettbegleitstoffe des Sanddornöls. Fett Wiss Technol 91:66-68. https://doi.org/10.1002/lipi.19890910205

Shrivastava A, Gupta V (2011) Methods for the determination of limit of detection and limit of quantitation of the analytical methods. Chron Young Sci 2:21. https://doi.org/10.4103/2229-5186.79345

Spink J, Moyer DC (2011) Defining the public health threat of food fraud. J Food Sci 76:R157-R163. https://doi.org/10.1111/j.1750-3841. 2011.02417.x

Sticher O (2008) Natural product isolation. Nat Prod Rep 25:517-554. https://doi.org/10.1039/b700306b

Teleszko M, Wojdyło A, Rudzińska M, Oszmiański J, Golis T (2015) Analysis of lipophilic and hydrophilic bioactive compounds content in sea buckthorn (Hippophaë rhamnoides L.) berries. J Agric Food Chem 63:4120-4129. https://doi.org/10.1021/acs.jafc.5b00564

Tiitinen KM, Yang B, Haraldsson GG, Jonsdottir S, Kallio HP (2006) Fast analysis of sugars, fruit acids, and vitamin $\mathrm{C}$ in sea buckthorn (Hippophaë rhamnoides L.) varieties. J Agric Food Chem 54:25082513. https://doi.org/10.1021/jf053177r

Publisher's Note Springer Nature remains neutral with regard to jurisdictional claims in published maps and institutional affiliations. 